\title{
Social media and its role in friendship-driven interactions among young people: A mixed methods study
}

\author{
Jean Philippe Décieux ${ }^{\mathrm{a}}$, Andreas Heinen ${ }^{\mathrm{b} *}$, Helmut Willems ${ }^{\mathrm{b}}$
}

${ }^{a}$ Chair for Empirical Research of Social Structure, University of Duisburg-Essen, Essen, Germany;

${ }^{b}$ Research Unit on Social and Individual Development (INSIDE), University of Luxembourg, Esch-sur-Alzette, Luxembourg;

* Corresponding author:

Andreas Heinen

University of Luxembourg

Maison des Sciences Humaines

11 , Porte des Sciences

Esch-sur-Alzette L-4365

Luxembourg

andreas.heinen@uni.lu 


\title{
Social media and its role in friendship-driven interactions among young people: A mixed methods study
}

\begin{abstract}
This article examines trends and developments in social interactions of young people and the role of social media in Luxembourg using a mixed method approach drawing on both quantitative and qualitative data. Our findings corroborate that social interactions via social media play a growing role in leisure time of young people and have changed the traditional patterns of friendship-driven social interactions between peers. We argue that although offline interactions remain very important for young people, they have been complemented and partially replaced by interactions via social media. Modes of young people's social media interactions can be characterised as mixed modalities.
\end{abstract}

Keywords: peers; social media; mixed methods; social interactions; leisure

\section{Introduction}

Peers are important agents of socialisation that provide a space for young people to gather life experiences mostly without direct interventions of adults. The importance of peers for young people is shaped by a discourse on risks and social deviance (e.g. violence, substance abuse, bullying) (Lachman, Roman and Cahill, 2012) but also by a discourse highlighting the importance of peers for the individual development and social integration of young people (Reitz, et al., 2014). In order to successfully get along in peer group settings and to form deeper relationships, young people have to cultivate social skills (e.g. communication, empathy, ability to balance own needs with needs of another person, morals, listening, observing) (Tillery et al., 2015). Peer relations form an important context in which young people receive feedback concerning their own social behaviour and thus have opportunities to learn how to participate actively in a group and to become acquainted with feelings of social affiliation and recognition (Rohlfs, 2010). Peers provide support (i.e. in times of difficulty or stress), motivation, competition, and companionship, in addition to serving as a setting for sharing times of joy or excitement 
(Cotterell, 2007). Hanging out and spending time with peers is associated with a need for communication and interaction. It is important for the construction, cohesion, and enhancement of peer relationships. Ethnographical or discourse analytical studies identify typical communication patterns ranging from joking or teasing and gossiping or mocking to the playful or serious solving of conflicts (Corsaro and Eder, 1990; Schmidt, 2004). Through practices like this, youth demonstrate their competences, demonstrate or negotiate their status within the peer group, and distinguish their peer group from third parties. Thus peer groups can be seen as communities of interaction that are formed and reproduced through routinized practices and encounters of young people (NeumannBraun and Deppermann, 1998).

Within recent years in most modern societies the increasing distribution and use of social media ${ }^{1}$ have modified the modes of social interactions (Donath and Boyd, 2004; Patulny and Seaman, 2016; Westlund and Bjur, 2014). New media, especially social media and instant messaging services, facilitate and change communication between peers (Lenhart et al., 2015). By using tools like tablets or smartphones, youth can be connected with others 'anywhere and at anytime' (Thulin 2017; Thulin and Vilhelmson, 2007; Wellman, 2004: 28). Social media today is used for a broad range of activities: to make appointments, to update each other, to share information or experiences, to selfpromote, to ask for feedback, and far many other things that cannot be fully explained in this paper (van Doorn, 2010; Grgic and Holzmayer, 2012; Livingstone, 2011). Most young people interact both online and offline and switch between these dimensions or even interact online and offline simultaneously (Granholm, 2016; Stald, 2008). Ito et al. (2010) distinguish between interest-driven and friendship-driven use of social media. In

\footnotetext{
${ }^{1}$ Social media are media technologies that allow the interpersonal exchange of information, ideas, experiences and other forms of expression (Obar and Wildman, 2015).
} 
interest-driven use, specialized activities and interests are the main reasons for use of the social media, but friendship-driven use is usually grown out of shared practices of friendships in given local social worlds. The focus of our study is on these friendshipdriven social media interactions of young people.

\section{Theoretical framework and research question}

From studies focusing on the exposure of new media we know that young people tend to be earlier adopters of digital communications and authoring capabilities than the older generations are, and that their exposure to new media is higher (Lenhart et al., 2008; Livingstone, 2011; Roberts and Foehr, 2008). Hence the increase of online communication in modern societies raises questions regarding its impact on young people's patterns of social interactions as well as on identity formation of this "digital generation" (Buckingham, 2008: 12; Ito et al., 2010). Familiar practices of making friends such as gossiping or jockeying for status are reproduced or even reshaped by the new opportunities of social media interactions which also allow for the extension of interactions with friends beyond physical activities (Boyd, 2010). In some way, absence from social media may also be a potential for exclusion (Boyd, 2008a). Some scholars evaluate the increase of online interactions rather negatively, highlighting that they have replaced offline interactions and lead to social isolation (Carrasco et al., 2008). Other studies reject this position, arguing that the 'fear' that interactions via social media create a socially isolating environment is 'unwarranted' (Quan-Haase and Wellman, 2004: 318), or finding a positive interpretation of online interactions as they facilitate the organization of social and community ties by saving time or money (Rettie, 2009). This positive interpretation is also related to the finding that, in many cases, online interactions do not completely replace offline interactions. Recent studies show that most online connections are based on offline networks and that offline interactions are not substituted but rather 
complemented by online interactions (Döring, 2010). Hence, young people are not increasingly isolated by their growing social media activity as the interactions are important for developing and maintaining friendships with peers (Boyd, 2010).Additionally, modes of interactions via social media are not necessarily isolated from the offline world. Most of the social interactions among peers can be characterized as "mixed modality" interactions in which elements of face-to-face communication are combined with elements of written, online communication (Baym, 2010).

Although offline and online interactions differ from each other (e.g. spatial distance and permanent accessibility as specific features of online interactions; Valkenburg and Peter, 2011), the development of social media (e.g. Facebook, Instagram, Snapchat, WhatsApp, Skype) has enhanced. Characteristics that were formerly exclusive to offline interactions have also become typical for online interactions. Social media platforms allow young people to convey friendliness, build intimacy, or express strong emotions (Baym, 2010).

Online interactions can take place via several channels simultaneously (text, audio, and video), and are characterized by a high richness of information, which reduces insecurity or ambiguity of information (Boyd, 2008a), and often have a comparatively high degree of synchronization (Dennis and Valacich, 1999, Thulin 2017). However, as Ito et al. (2010) revealed, we are still at the early stages of piecing together the picture of the role of social media in young people's everyday lives and the modes of interactions due to social media. The central aim of this paper is to investigate the role of social media for social interactions among young people. More precisely we focus on friendshipdriven use of social media. Friendship-driven social media activities include contexts of leisure as well as school, religious groups, sports clubs and other activity groups that are usually the primary source of affiliation, friendship, and romantic partners. 
In a first step, we elucidate to what extent peer interactions have changed in the course of the dissemination of social media. Second, we investigate why young people use social media for peer interactions by analyzing the different motives driving social media use. Third, we explore in what way social media has changed peer interactions and whether use of social media might be a substitution for or might complement offline interactions among peers.

\section{Data, methods, and samples}

Our analyses are based on a mixed method approach in which both quantitative and qualitative research data are used. Quantitative data come from four waves $(2008,2011$, 2014, and 2016) of the 'Plan Communal Jeunesse' Luxembourg trend survey, which is a longitudinal survey for young people in different municipalities in Luxembourg (Heinen et al., 2009; Meyers, Heinen and Berg, 2012; Kremer, Heinen and Willems, 2014; Décieux, Heinen and Willems, 2016). The samples of all four waves of the trend survey were convenience samples consisting of young persons between 15 and 25 years of age. The sample size for wave 2008 was $n=277$, for $2011 n=453$, for $2014 n=164$ and for $2016 n=209$. With regard to gender, all samples were balanced. These data allow the detection and documentation of social trends and changes in peer interactions on an aggregated population level (Ruane, 2016). ${ }^{2}$

This quantitative perspective is complemented by qualitative data that were collected in follow-up interviews of the 2016 'Plan Communal Jeunesse' (Décieux,

\footnotetext{
${ }^{2}$ Concerning data of the trend survey it would have been interesting to compare developments in the frequency of activities. This was not possible, because of a break in the scale of these items in 2013. Before 2013 we asked the frequency of activities by using a Likert scale ranging from "never/does not apply" to "very often"; after 2013 we used a scale ranging from "never/does not apply" to "everyday/several times a day". Thus, it was only possible to rank the importance compared to other activities. Also it was not possible to monitor individual developments as the sample of the trend survey varied.
} 
Heinen and Willems, 2016). A total of four focus group discussions were conducted: Three focus groups consisted of young people $(N=16)$ between 15 and 25 years old and of various nationalities, education, and gender. One expert focus group consisted of 12 youth experts (e.g. youth policy makers, youth professionals, representatives of sport clubs, schools and young people). Data gathered through the qualitative approach were analysed using qualitative content analysis with a mixed strategy of deductive and inductive category development (Kohlbacher, 2006; Kuckartz, 2012).

This combination of different methods within our empirical approach offers the opportunity to generate a vast amount of data and to structure it along our analytical framework (Freshwater, 2014; Hesse-Biber and Johnson, 2013; McKim, 2017).

\section{Results}

\section{The increase of the importance of peer interactions via social media}

Participants of the trend survey were asked how often they spend their leisure time in certain activities. The trend survey shows some major changes between the different waves with regard to the ranking of the most important activities during leisure time (Figure 1). In 2008, 'meeting up with friends' was ranked as the most important activity. Media activities like 'listening to music' and 'using the internet' were rated as second and third most important leisure activities. These three activities remained most important according to rankings reported in 2011. However, in 2016 this rank order changed considerably. Whereas the activities 'listening to music' and 'internet' remained at the top, meeting up with friends' sharply decreased. In 2016, it was only the sixth most important leisure activity of youth in Luxembourg. Other media use, such as 'playing a game on the computer, mobile or gaming console' or other mobile device activities (e.g. 
'photographing and filming') gained frequency. Furthermore, in the same period, 'relaxing alone' became more and more important, being ranked as the fifth most common leisure activity in 2016 . Therefore, with regard to social contact and interactions with friends the results show that meeting friends in person has become less important for the interviewed young people, whereas spending time alone has become a more common leisure activity among them.

Figure 1: Ranking of important leisure activities among young people between 2008 and 2016

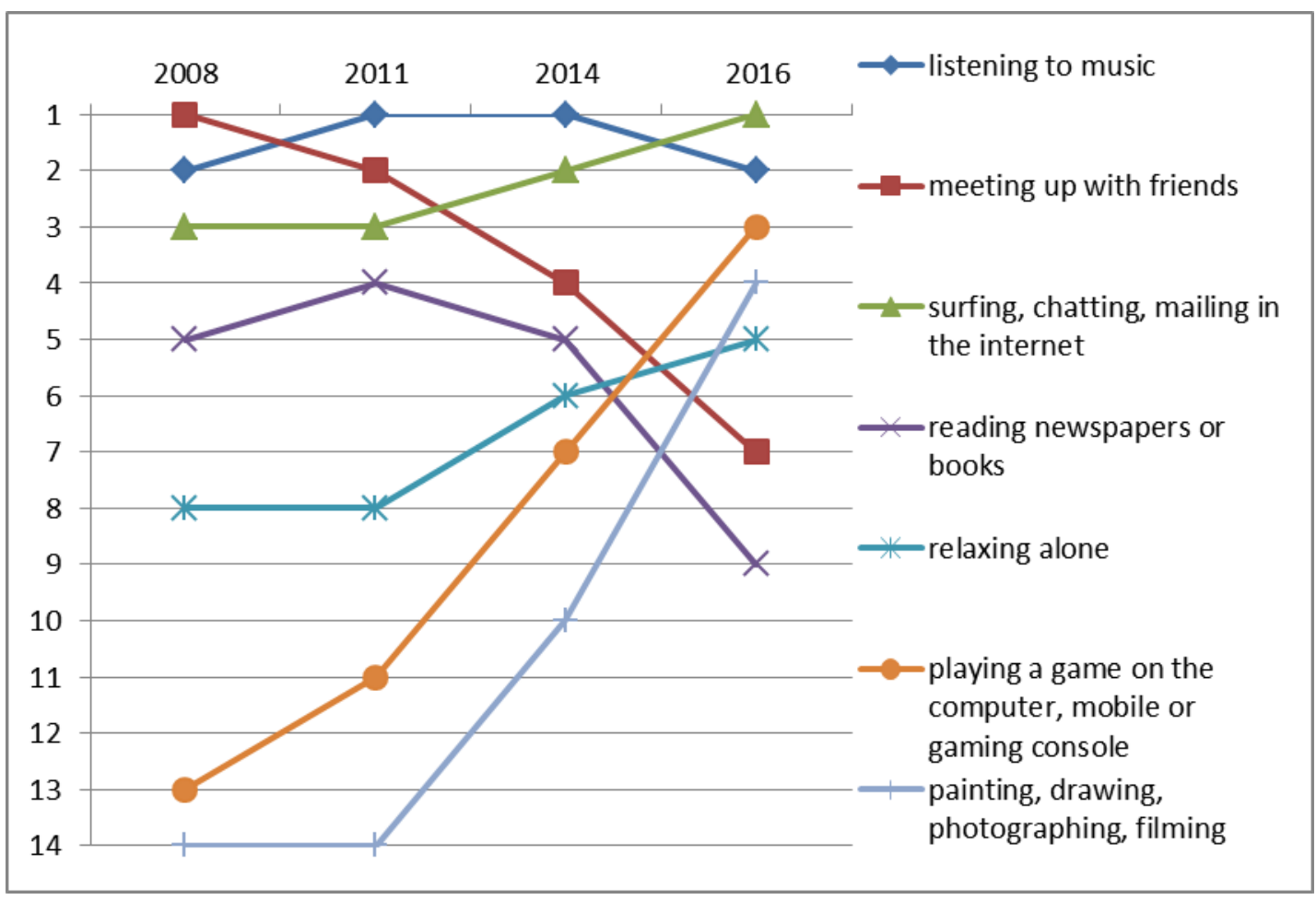

Sources: Heinen et al., 2009; Meyers, Heinen and Berg, 2012; Kremer, Heinen and Willems, 2014; Décieux, Heinen and Willems, 2016.

In Wave 2016 young people had to scale different reasons they use the internet and social media on a five-point Likert scale (1 "everyday/several times a day" to 5 "never/does not apply"). Here it became obvious that social media are not only used for information gathering and entertainment, but especially for interacting with friends. 
Three out of four (76.1\%) young people stated that they very often or often use the internet 'to interact with others' or 'to stay in contact with others'. Thus, these items represent the most frequent internet activities of Luxembourgish young people in 2016 and, compared to reports from the 2010 and 2014 waves, the frequency of these activities has increased considerably.

The high importance of social media for young people in Luxembourg is supported by other research findings. According to a study of the Luxembourgish Institute of Statistics and Economic Studies, 83.4\% of young people in Luxembourg are registered in a social network (e.g. Facebook, Twitter, LinkedIn; Frising, 2012). The results of the EU statistics on income and living conditions (EU-SILC) in 2015 for Luxembourg show a similar trend. ${ }^{3}$ With a share of $81.5 \%$, a large majority of young people between 16 and 24 years of age use social media on a daily basis.

These results are twofold: On the one hand, the frequency of offline contact with friends during leisure time has obviously decreased. On the other hand, at the same time, social media and digital devices (internet, mobile phones) have become increasingly important for young people during their leisure time. Social media are an integral part of young people's everyday life since a majority of them use social media for social interactions and to stay in touch with their friends (Handyside and Ringrose, 2017).

These results suggest that social interactions have changed in that a shift from offline interactions to interactions via social media has taken place to some degree. The results of our focus group discussions offer further insights into the reasons young people use social media tools for interactions with friends and how social media have changed patterns of peer interactions.

3 http://ec.europa.eu/eurostat/web/income-and-living-conditions/data/ad-hoc-modules (last accessed 17 October 2017) 


\section{Why do young people choose social media for peer interactions? Motives and reasons}

Based on the qualitative data, we were able to deduce motivational dimensions of young people's choice for using social media for interactions instead of meeting friends in person to interact offline. We sorted quotations in which interviewees described their motives for using the internet into categories, including both pre-set, anticipated motives and emerging coding categories. In the course of this process of categorization and aggregation of data, two main motivational dimensions were extracted: the (a) low effort of the use of social media for interactions and (b) its ubiquity, meaning social media being present in young people's life 'anywhere and anytime'.

\section{Low effort of interactions via social media}

The first motivational dimension is based on the finding that young interviewees emphasized different aspects such as a low time investment, the ease of use, and a low motivation to meet peers physically as pertinent motives for the use of social media.

| 'It costs a lot of time if you meet each other, to discuss some things.' (focus group 1)

'I have a lot of friends living in other municipalities and then it is easier to communicate with them via Facebook or smartphone while you are lying on your bed than to go out and meet your friend' (focus group 4)

All these aspects can be categorized under the dimension of low effort of interactions via social media. The comments make obvious that the effort to interact via social media is considered to be much lower than offline. Hence, for young people social media interactions are a very time-effective alternative to interact and to stay connected with their friends. This is also reflected by the statement of an interviewee whose preferred 
channel of interaction is social media, even though his peers live close in the neighborhood and the effort to meet in person would be rather low.

'For example I have a friend that lives about 100 meters away from me. And very often we both are not motivated to visit each other at home. The consequence then is that we send each other messages however the effort of 100 meters between us is very low... we do not meet but we write messages' (focus group 2)

Young interviewees also specified that social media interactions are very comfortable for them as they can interact with their friends while they are doing other things.

'It is certainly more comfortable to send a message here and there. I often do that while I am doing other things. In addition, it costs time and effort to meet friends in person. Very often you are too lazy after a long day at school. Then you prefer to write some messages to update each other.' (focus group 1)

The importance of social media use is strongly related to general leisure time arrangements. The interviewees stated that they have a lot of commitments. Besides going to school, young people do extracurricular activities such as sports, music, or other activities in local associations. These activities are important opportunities to meet and to spend time with peers. Interviewees reported that the leisure activities are very time consuming and sometimes stressful for them so that they need time to relax and to spend time alone (see also the results of the quantitative analysis). During days with a tight schedule, use of social media allows young people to exchange information easily, without spending a lot of time to get to the place of a meeting and without the duty to spend time for more than the exchange of information. In these ways, social media are embedded in young peoples' everyday life. They do not have to interrupt their original activity to interact, because in most cases social media interactions can take place simultaneously alongside other activities. Additionally, young people often prefer this 
form of interaction, as it is fast, focused on the main subject of the interaction, and therefore more comfortable to use.

'You normally do not meet to report three things. Then it is more comfortable to send three messages because this takes three minutes' (focus group 1)

Social media are considered to be very effective, requiring only a low time investment, to interact with friends. The findings indicate a relationship between available time and the use of social media for interactions in the sense that the more the available leisure time is limited, the higher the attractiveness of social media becomes.

\section{Ubiquity of social media: "anytime and anywhere"}

Another dimension refers to the wide distribution and ubiquity of social media in young people's life. Young people are connected to social media tools and by this to their peers "anytime and anywhere". Thus, in the focus groups, young people stated that most of their friends share their life and experiences on social media networks like Facebook or Instagram pages. For this reason, there is often no need to meet each other (for example, after holidays) to exchange stories, as friends have the feeling that they already know the most important stories from social media.

'Yes, but I think after your holidays you may not have to talk about your holidays. Most of the things happened have already been posted on Instagram or Facebook and you know them.' (focus group 3)

Social media leads to a temporal advantage and young people are up-to-date concerning the important things that happened to their friends. They can exchange news immediately with their peers and do not have to wait until they meet them in person. This can strongly affect interaction patterns, as it decreases the benefits of direct offline interactions. In this case, a complete substitution of offline interactions can take place depending on the extent of the general social media activity of young people. 
Another young interviewee mentioned an example that illustrates how the ubiquity of social media affects the way young people communicate with each other. Social media can make specific topics of an offline interactions superfluous.

'I think it is obvious that social media changed the ways how people interact. For example, when you come home from holidays you nearly know all stories your friends experienced because they have been documented on Facebook or Instagram and you say 'I already saw that' ... It is often like that; the discussions topics are gone because of social media.' (focus group 3)

\section{Social interactions among peers as mixed modalities}

The motives specified above provide further insight into the way social media affect peer interactions. First, the data allowed us to identify the specific attractiveness of social media. Social media interactions provide a wide range of new opportunities for a differentiated exchange or sharing of information. It offers many alternatives to simply using words, whether by writing things down or talking. Interviewees highlighted that diverse features of social media (photos, videos) make the interactions more visual and alive.

'I would say the ways of communication changed because of the various possibilities of communication we have. You do not have to meet your friends to communicate. Video conferences are really working well via Skype!' (focus group 3)

'Today you can make really nice photos with your mobile phones. This offers an easy opportunity to share them with your friends.' (focus group 2)

As tools like Skype, WhatsApp, or Facebook (Messenger) offer opportunities to see or hear each other and to communicate non-verbal elements online interactions are not only considered as being easy to start but also being 'natural' in a way. Thus, the statements indicate that features of social media make the interactions via social media to some extend similar to offline interactions. 
However, despite the similarities between online and offline interactions, young people stated in the focus group discussions that they made their friends offline within traditional institutions of secondary socialization. They specified that they know most of their peers from school, their neighborhood, associations, or other offline contexts.

| 'I know my best friends from school or from football.' (focus group 1)

'I had contact with people from my municipality until I was 16 or 17. Later, most of my friendships based on school.' (focus group 2)

'Some of my best friends I know from primary school, but the rest of my friends I mostly know from school. ... And I would say that it is usually like that, that friendships in youth mostly base on schoolmates.' (focus group 2)

Meeting people in person and to interact offline are considered to be important prerequisites to develop friendships. Additionally, young people meet friends in person if they have enough time and there are no other obligations, for example during the holidays or over the weekend.

'During their holidays, I think most of the young people do a lot with their friends and much more often than in a normal school week.' (focus group 4)

This is especially true for specific leisure activities, which require physical presence; they mentioned here examples like football or going to the cinema.

'There are still some things that you cannot do via Facebook or things like that. For example, playing football with your friend or going to the cinema. You can't do things like that on Facebook!' (focus group 1)

In total opportunities to meet face-to-face in an offline setting and direct interactions still seem to be very important for young people to make friends, to form a peer group, and to interact with each other.

Thus, our results point out, that social media interactions are strongly linked to the offline daily life and underpin the argument that social media are used as a complementary tool 
for social interactions among young people. On the one hand, social media interactions have characteristics of offline interactions, and on the other hand social media is used to interact with friends that young people made offline.

In summary, online and offline interactions are mutually interrelated so that the mode of interaction via social media can be characterized as mixed modalities.

\section{Discussion}

Our results for Luxembourg are consistent with the findings of recent studies in other countries such as Döring (2010), Granholm (2016), Grgic and Holzmayer (2012), Thulin (2017) and Patulny and Seaman (2016), who found an increasing role of online communication and social media for interactions. Our findings indicate that the dissemination of social media and mobile devices has not lead to a complete disappearance of offline interaction between peers. Offline interactions are an integral part of young people's leisure activities. However, we were able to determine that offline interactions are partially substituted but also complemented by interactions via social media. Thus, our results are in line with Ito et al. (2010), describing that youth social media activity replicates existing practices of hanging out and communicating with friends, but creates new kinds of opportunities due to the new facilitating possibilities of social media. However, we see no indication that social media are changing the fundamental nature of friendship practices (Boyd, 2010).

Based on the results of our study, we found different motives for social media use. First, young people use social media for peer interactions as it is a time-effective alternative to meeting friends in person. Here our results are in line with Rettie (2009) as well as with Boyd (2008a), who showed that the choice for a mode of interaction depends on several tradeoffs, ranging from time calculations to the importance of the interaction. 
A second motive is the ubiquity of social media (Lievrouw and Livingstone, 2006), or its availability "anytime and anywhere" (Wellman, 2004: 28).

Due to these specific characteristics, social media are particularly popular for young people's social interactions and are of great importance in their daily life. Young people present their life and experiences, and in this way they can share them with their peers. Due to the opportunity to share information and experiences on social media pages, there is often no more need to meet in person.

Concerning the question of how social media changed young people's interactions, our results show that, on the one hand, the visual contents of social media offer opportunities to communicate a message in a greatly differentiated way. Use of visual contents makes the interactions rich in information and increases the social presence of the interacting persons (Kaplan and Haenlein, 2010; Thulin 2017). On the other hand, young people make friends within traditional contexts of offline interactions like schools or sports clubs, and it is these relationships that form the base for further interactions that take place via social media (Boyd, 2008a; 2010). This finding is consistent with Döring (2010), who found a strong relationship between young people's online and offline networks. Boyd (2008 a,b; 2010) and Awan and Gauntlett (2013) also stated that interactions that begin in person do not end when friends are separated because of social media. They can for example be continued on a complementing social media messaging channel. Thus they are a kind of extension or complementation of offline interactions. For most of our cases, offline and online modes of friendship-driven interaction, can interpreted as Baym (2010) proposed, as "mixed modalities". Additionally, young people stated that they often prefer direct offline interactions if there is enough time, and that there are also specific situations that require or when they prefer physical presence so that interactions take place offline. Recent studies have also shown 
that most young people see social media activities not as integral for their friendship, but as a simple and easy opportunity for friendship-driven actions and to strengthen bonds of existing friendships (Awan and Gauntlett, 2013; Boyd, 2008b).

Overall, the patterns of interactions between youth changed due to social media. Young people increasingly often use social media tools to keep in touch with their friends and to interact with their peers. Social media can be interpreted as a 'technology of distance', as they offer the opportunity to easily interact across physical or social distances.

\section{Limitations and outlook}

Our findings represent a specific case, a convenience sample of youth in Luxembourg. Although it is not representative for youth per se, this exemplary sample group can be seen as a typical case of young people living in a western society.

The study presents a general approach of young people's friendship-driven interactions and their use of social media. Therefore it could neither take into account the diversity of social media offers nor the specific practices of their use (Donath and Boyd, 2004). It would be worthwhile to expand these issues for investigation through further research for instance by investigating the relationship between subjects of interaction and the preferred mode (online/offline). Furthermore, it would be important not only to focus on the positive aspects and benefits of online interactions but to investigate also the negative aspects and specific problems related to online interactions (such as harassment, cyberbullying, sexting, phubbing) which are exclusive and specific problems of this medium (Keipi, 2017).

The mixed method design of this study is a strength, and it allows us to corroborate the developments in peer interactions of young people and explore reasons for these 
developments referring to a vast amount of complementary empirical data. Based on these results, it would be worthwhile to go deeper into the analysis of the consequences of the use of social media for the quality of peer relations.

\section{Acknowledgements}

Research for this article was kindly funded by the Luxembourgish Ministry of Education, Children and Youth and the municipality of Strassen (Luxembourg). The authors wish to thank the reviewers of Young who offered helpful suggestions on this article and Amanda Seyle Jones for final proofreading.

\section{References:}

Awan, F. \& Gauntlett, D. (2013) Young People's Uses and Understandings of Online Social Networks in Their Everyday Lives. Young, 21(2), 111-132. doi: $10.1177 / 1103308813477463$

Baym, N. (2010). Personal connections in the digital age. Malden, MA: Polity Press.

Boyd, D. (2008a) Why youth love social network sites: The role of networked publics in teenage social life." in D. Buckinham (ed.), Youth, identity, and digital media, Cambridge, MA: The MIT Press, 119-42.

Boyd, D. (2008b) Taken Out of Context: American Teen Sociality in Networked Publics. University of California: Berkeley.

Boyd, D. (2010) Friendship. in Ito, M., Baumer, S., Bittanti, M., Boyd, D., Cody, R., Herr-Stephenson, B., Horst, H.A. et al.. (eds.), Hanging out, messing around, and 
geeking out: Kids living and learning with new media. Cambridge, MA and London: MIT Press.

Buckingham, D. (2008) Introducing Identity. in D. Buckinham (ed.). Youth, identity, and digital media, Cambridge, MA: The MIT Press, 1-24.

Carrasco, J. A., Hogan, B., Wellman, B. \& Miller, E. J (2008) Agency in Social Activity Interactions: The Role of Social Networks in Time and Space. Tijdschrift voor Economische en Sociale Geografie. 99, 562-583. doi:10.1111/j.14679663.2008.00492.x

Corsaro, W. A. \& Eder, D. (1990) Children's Peer Cultures. Annual Review of Sociology 16(1), 197-220. doi:10.1146/annurev.so.16.080190.001213

Cotterell, J. (2007) Social networks and social influences in adolescence. Adolescence and society. London: Routledge.

Décieux, J. P., Heinen, A. \& Willems, H. (2016) Youth in the municipality of Strassen. Developments, problems and perspectives [Die Jugend der Gemeinde Strassen. Entwicklungen, Probleme und Perspektiven]. Luxembourg: University of Luxembourg.

Dennis, A. R. \& Valacich, J. S. (1999) Rethinking media richness: towards a theory of media synchronicity. Proceedings of the 32nd Hawaii International Conference on System Sciences - 1999, 1-10. doi:10.1109/HICSS.1999.772701

Donath, J. \& Boyd, D. (2004) Public displays of connection. Technology Journal 22 (4),71-82. doi: 10.1023/B:BTTJ.0000047585.06264.cc 
Döring, N. (2010) Social contacts online: Identities, relations, communities [Sozialkontakte online: Identitäten, Beziehungen, Gemeinschaften]. In W. Schweiger \& K. Beck (eds.), Handbuch Online-Kommunikation [Handbook OnlineCommunication]. Wiesbaden: VS Verlag für Sozialwissenschaften, 159-183.

Freshwater, D. (2014) What Counts in Mixed Methods Research: Algorithmic Thinking or Inclusive Leadership? Journal of Mixed Methods Research, 8(4): 327-329. doi: $0.1177 / 1558689814553092$

Frising, A. (2012) The use of ICT at a glance [Regards sur l'utilisation des TIC par les particuliers]. Regards du STATEC, (14) : 1-4.

Granholm, C. (2016) Blended Lives. ICT Talk among Vulnerable Young People in Finland (2016) Young, 24(2): 85-101. doi: 10.1177/1103308815613188

Grgic, M. \& Holzmayer, M. (2012) Between Football and Facebook [Zwischen Fußball und Facebook] DJI Impulse, 3 (99): 18-21.

Handyside, S. \& Ringrose, J. (2017) Snapchat memory and youth digital sexual cultures: mediated temporality, duration and affect. Journal of Gender Studies, 26(3), 347-360. doi: $10.1080 / 09589236.2017 .1280384$

Heinen, A., Meyers, C., Meisch, N. \& Willems, H. (2009) Youth in the municipalities of Sandweiler and Contern: Final report of the youth study in the context of the interlocal youth plan for the municipalities of Sandweiler and Contern [Die Jugend in den Gemeinden Sandweiler und Contern: Abschlussbericht zur Jugendstudie im Rahmen des interkommunalen Jugendgemeindeplanes für die Gemeinden Sandweiler und Contern] Walferdange: University of Luxembourg. 
Hesse-Biber, S. \& Johnson, R. B. (2013) Coming at Things Differently: Future Directions of Possible Engagement With Mixed Methods Research. Journal of Mixed Methods Research, 7(2), 103-109. doi: 10.1177/1558689813483987

Kaplan, A. M., \& Haenlein, M. (2010) Users of the world, unite!: The challenges and opportunities of Social Media. Business Horizons, 53(1), 59-68. doi:10.1016/j.bushor.2009.09.003

Keipi, T. (2017) Relatedness Online. An Analysis of Youth Narratives Concerning the Effects of Internet Anonymity. Young, 26(2), 1-17. doi: 10.1177/1103308817715142

Kohlbacher, F. (2006) The use of qualitative content analysis in case study research. Forum: Qualitative Social Research, 7(1). Available from: http://nbnresolving.de/urn:nbn:de:0114-fqs0601211 [Accessed 17 October 2017].

Kremer, L., Heinen, A. \& Willems, H. (2014) Youth of the municipality of Schüttringen - Developments and perspectives: Final report of the youth study in the context oft he local youth plan for the municipality of Schüttringen [Die Jugend der Gemeinde Schüttringen - Entwicklungen und Perspektiven: Ergebnisbericht der Jugendstudie im Rahmen des Jugendkommunalplans für die Gemeinde Schüttringen]. Walferdange: University of Luxembourg.

Kuckartz, U. (2012) Qualitative Content Analysis. Methods, Practice and Computer Assistance [Qualitative Inhaltsanalyse. Methoden, Praxis, Computerunterstützung]. Weinheim: Juventa Verlag.

Lachman, P., Roman, C. G., \& Cahill, M. (2012) Assessing Youth Motivations for Joining a Peer Group as Risk Factors for Delinquent and Gang Behavior. Youth Violence and Juvenile Justice, 11(3), 212-229. doi:10.1177/1541204012461510 
Lenhart, A., Arafeh, S., Smith, A., \& Macgill, A.R. (2008) Writing, Technology and Teens. Pew Internet \& American Life Project. Washington, DC. Available from: http://www.pewinternet.org/files/oldmedia/Files/Reports/2008/PIP_Writing_Report_FINAL3.pdf.pdf [Accessed 16 October 2017]

Lievrouw, L., \& Livingstone, S. (2006) Introduction. in L. Lievrouw \& S. Livingstone, (eds.), Handbook of New Media: Social Shaping and Social Consequences. London: Sage, 1-14.

Livingstone, S. (2011) Internet, children, and youth. in M. Consalvo, \& C. Ess. (eds.) The Handbook of Internet Studies. Oxfrod: Wiley-Blackwell, 348-68.

McKim, C. A. (2017) The Value of Mixed Methods Research: A Mixed Methods Study. Journal of Mixed Methods Research, (11)2, 202-222. doi: $10.1177 / 1558689815607096$

Ito, M., Baumer, S., Bittanti, M., Boyd, D., Cody, R., Herr-Stephenson, B., Horst, H.A. et al. (2010) "Hanging out, messing around, and geeking out: Kids living and learning with new media.". Cambridge, MA and London: MIT Press. Available from: $\underline{\text { https://dmlcentral.net/wp-content/uploads/files/Hanging_Out.pdf }}$ [Accessed 16 October 2017].

Lenhart, A., Smith, A., Anderson, M., Duggan, M. \& Perrin, A. (2015) "Teens, Technology and Friendships." Pew Research Center. http://www.pewinternet.org/2015/08/06/teens-technology-and-friendships [Accessed 16 October 2017]. 
Meyers, C., Heinen, A. \& Berg, C. (2012) Youth of the municipality of MerschDevelopments and perspectives: Final report of the youth study in the context oft he local youth plan for the municipality of Mersch [Die Jugend der Gemeinde Mersch. Entwicklungen und Perspektiven: Ergebnisbericht der Jugendstudie im Rahmen des Jugendkommunalplanes für die Gemeinde Mersch]. Walferdange: University of Luxembourg.

Neumann-Braun, K. \& Deppermann, A. (1998) Ethnography of the communication culture of youth [Ethnographie der Kommunikationskulturen Jugendlicher]. Zeitschrift für Soziologie, 27(4), 239-255.

Obar, J. A. \& Wildman, S. S. (2015) Social media definition and the governance challenge: An introduction to the special issue. Telecommunications Policy, 39(9), 745-750. doi:10.1016/j.telpol.2015.07.014

Patulny, R. \& Seaman, C. (2016) 'I'll just text you': Is face-to-face social contact declining in a mediated world? Journal of Sociology, 53(2), 1-18. doi:10.1177/1440783316674358

Quan-Haase, A. \& Wellman, B. (2004). How Does the Internet Affect Social Capital. in M. Huysman \& V. Wulf (eds.), Social Capital and Information Technology. Cambridge, MA: MIT Press, 113-135.

Reitz, A. K., Zimmermann, J., Hutteman, R., Specht, J. \& Neyer, F. J. (2014). How Peers Make a Difference: The Role of Peer Groups and Peer Relationships in Personality Development. European Journal of Personality, 28(3), 279-288. doi:10.1002/per.1965 
Rettie, R. (2009) Mobile Phone Communication: Extending Goffman to Mediated Interaction. Sociology, 43(3), 421-38. doi:10.1177/0038038509103197

Roberts, D. F. \& Foehr U.G. (2008) Trends in Media Use. The Future of Children, 18(1), 11-38. doi: $\underline{10.1353 / \text { foc. } 0.0000}$

Rohlfs, C. (2010) Friendship and affiliation - Basic need, developmental task and challenge for school education [Freundschaft und Zugehörigkeit - Grundbedürfnis, Entwicklungsaufgabe und Herausforderung für die Schulpädagogik]. in M. Harring, M., O. Böhm-Kasper, C. Rohlfs \& C. Palentien (eds.), Freundschaften, Cliquen und Jugendkulturen. Wiesbaden: VS Verlag für Sozialwissenschaften, 61-72.

Ruane, J. M. (2016) Introducing social research methods: Essentials for getting the edge. Chichester: John Wiley \& Sons.

Schmidt, A. (2004) Doing peer-group: The interactive constitution of youth group practice [Doing peer-group: Die interaktive Konstitution jugendlicher Gruppenpraxis] Europäische Hochschulschriften Soziologie Bd. 399. Frankfurt am Main: Lang.

Stald, G. (2008) 'Mobile Identity: Youth, Identity, and Mobile Communication Media', in D. Buckingham (ed.) Youth, Identity, and Digital Media. Cambridge, MA: The MIT Press, 143-64.

Thulin, E. (2017) Always on My Mind: How Smartphones are Transforming Social Contact among Young, Young, 26(5), 1-19. doi: 10.1177/1103308817734512

Thulin, E. \& Vilhelmson, B. (2007) 'Mobiles Everywhere: Youth, the Mobile Phone, and Changes in Everyday Practice', Young, 15(3), 235-253. doi:

$10.1177 / 110330880701500302$ 
Tillery, R., Cohen, R., Parra, G. R., Kitzmann, K. M. \& Howard Sharp, K. M. (2015) Friendship and the Socialization of Sadness. Merrill-Palmer Quarterly, 61(4), 486508.

Valkenburg, P. M. \& Peter, J. (2011) Online Communication Among Adolescents: An Integrated Model of Its Attraction, Opportunities, and Risks. Journal of Adolescent Health, 48 (2), 121-27. doi:10.1016/j.jadohealth.2010.08.020

van Doorn, N.A.J.M. (2010) Digital Spaces, Material Traces: Investigating the Performance of Gender Sexuality, and Embodiment on Internet Platforms that feature User-Generated Content. PhD thesis, The University of Amsterdam. URL (consulted on 24 January 2018): https://pure.uva.nl/ws/files/1041657/72912_thesis.pdf

Wellman, B. (2004) Connecting Communities: On and Offline. Contexts, (4), 22-28. doi: $10.1525 /$ ctx.2004.3.4.22

Westlund, O. \& Bjur, J. (2014). Media Life of the Young. Young, 22(1), 21-41. doi:10.1177/1103308813512934 